\title{
ISOPERIMETRIC INEQUALITY IN TAXICAB GEOMETRY
}

\author{
İSMAIL KOCAYUSUFOĞLU
}

\begin{abstract}
The history of the Isoperimetric Inequality goes back to 900 BC. Mainly, the Isoperimetric Theorem states that "Among all planar shapes in Euclidean geometry, the circle is the best figure in the plane".

In this paper, we proved the theorem for Taxicab geometry. Surprisingly (there is a reason), "Among all planar shapes in Taxicab geometry, the (taxicab) square is the best figure in the (taxicab) plane".

"The circle is the most simple, and the most perfect figure." DANTE.
\end{abstract}

Mathematics subject classification (2000): 26D20, 26D99, 52A40.

Key words and phrases: Taxicab geometry, isoperimetric inequality.

\section{REFERENCES}

[1] E. F. Krause, Taxicab Geometry, Addison-Wesley, Menlo Park, NJ, (1975).

[2] I̊. KocayusufoĞLU, Z. AKCA AND C. EKICI, The Inner-Product in Taxicab Geometry, Mathematics, Mechanics and Informatics, (1998).

[3] İ. KocayusufoĞLu, Some Area Problems in Taxicab Geometry, Jour. of Inst. of Math and Comp. Sci., 12, (1999), 95-98.

[4] J. BoGAERT, Isoperimetric Geometry, hPUMAS, ID 01_22_03_1, (2003). 